\title{
High stability field emission from zinc oxide coated multiwalled carbon nanotube films
}

\author{
Rajkumar Patra, Santanu Ghosh ${ }^{\star}$, Himani Sharma, Vasant D. Vankar \\ Nanostech Laboratory, Department of Physics, Indian Institute of Technology Delhi, New Delhi 16, India \\ *Corresponding author. Tel: (+91) 11 26591348; Fax: (+91) 26581114; E-mail: ghoshsantanu1@yahoo.co.in
}

Received: 08 April 2013, Revised: 21 May 2013 and Accepted: 08 June 2013

\section{ABSTRACT}

A comparative study of electron field emission (FE) property of pristine mutiwalled carbon nanotubes (p-CNTs), zinc (Zn) coated CNTs (Zn-CNT), zinc oxide (ZnO) coated CNTs (ZnO-CNT) is reported. CNTs were synthesized on p-type Si (100) by microwave plasma enhanced chemical vapor deposition (MPECVD) method and the sample was divided into three parts. On two of these parts, a thin layer $(\sim 4 \mathrm{~nm})$ of $\mathrm{Zn}$ film was deposited. One of these (Zn-CNT) was kept for analysis and the other one was annealed in oxygen $\left(\mathrm{O}_{2}\right)$ atmosphere at $520^{\circ} \mathrm{C}$ for 60 minutes to get $\mathrm{ZnO}$ coated CNT film $(\mathrm{ZnO}-\mathrm{CNT})$. Scanning electron microscope (SEM) analysis confirmed CNT formation as well as Zn and ZnO coating on the top of p-CNT films. Further, energy-dispersive X-ray spectroscopy (EDX) results confirmed the presence of zinc and oxygen in these two samples. A detailed field emission study performed in these films give following results: (i) lowest turn-on field (electric field required to produce $10 \mu \mathrm{A} / \mathrm{cm}^{2}$ current density) and threshold fields (electric field required to produce $100 \mu \mathrm{A} / \mathrm{cm}^{2} \mathrm{current}$ density) for pristine sample $(3.3 \mathrm{~V} / \mu \mathrm{m}$ and $5.1 \mathrm{~V} / \mu \mathrm{m}$ respectively), followed by ZnO-CNT sample $(3.7 \mathrm{~V} / \mu \mathrm{m}$ and $6.3 \mathrm{~V} / \mu \mathrm{m}$ respectively); (ii) highest temporal stability in current density versus field (J-E characteristics) in ZnO-CNT film as compared to other two, (iii) highest field enhancement factor in ZnO-CNT films as compared to other two. The FE results are correlated with microstructures of the samples as revealed by micro-Raman spectroscopy and transmission electron microscopy (TEM) studies. Copyright (C) 2013 VBRI press.

Keywords: Carbon nanotube; field emission; raman spectroscopy; zinc oxide; TEM.
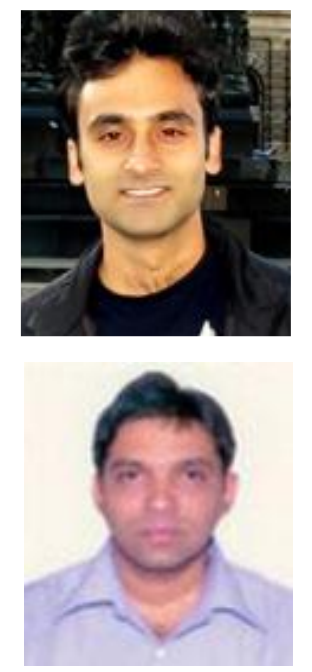

Santanu Ghosh is currently an Associate Professor in the Department of Physics, Indian Institute of Technology Delhi, India. He obtained his Ph.D. in Physics from Nuclear Science Centre, New Delhi, India His present research interests are Thin Films, Nanodimensional growth materials, Ferromagnetic semiconductor, Magnetic nanocomposites and modification of materials with energetic ions.

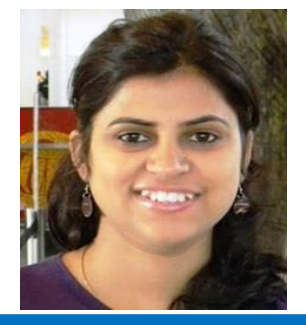

Himani Sharma received her $\mathrm{Ph}$. D degree in Physics (2012) from Indian Institute of Technology Delhi, India. Presently, she is working as a postdoctoral fellow in University of Alberta. Her research work is focused on the carbon dioxide photoreduction.

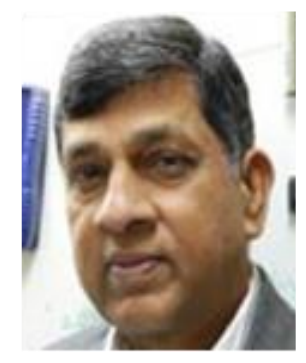

Vasant D. Vankar is currently a Professor Emeritus in the Department of Physics, Indian Institute of Technology Delhi, India. He obtained his Ph.D. in Physics from Banaras Hindu University, Varanasi, India. His research interests are in Nanotechnology, Carbon Nanotubes and Graphene thin films, plasma processing of materials, solid state interfaces, phase change materials for optical recording, hard coating, macro-crystalline diamond, diamond like Carbon and surface physics. In these areas of research, he has published about more than 130 research papers in International Journals and One US Patent on Boron Nitride and related coatings.

\section{Introduction}

The unique fundamental physical properties and potentially high-technology application made one dimensional (1D) nanostructured materials in the center of attraction for a long time [1]. Since the discovery of carbon nanotubes (CNTs) [2], they are the most promising field emitters (first reported in 1995) [3] to be used in the future field emission display (FED) devices due to their high aspect ratio, small tip radius curvature [4-7]. Field emission (FE) is a quantum mechanical process where electrons near the Fermi level can tunnel through the energy barrier and escape to the 
vacuum level under a high enough electric field. These unique properties of CNTs make them remarkable field emitters. The field emission process is governed by Fowler-Nordheim $(\mathrm{F}-\mathrm{N})$ equation [8],

$$
I=\frac{a \beta^{2} V^{2}}{\varphi d^{2}} \exp \left(-\frac{b d \varphi^{\mathrm{s} / 2}}{\beta V}\right)
$$

where parameters are emission current $(I)$, applied voltage $(V)$, work function of the material $(\varphi)$, distance between anode and cathode $(d)$, and field enhancement factor $(\beta)$, which is defined as ratio of local electric field and macroscopic electric field. The emission current can be easily tuned by varying work function of the emitting material by depositing thin metal films on CNT films [910], decorating CNTs with metal nanoparticles [11], or by making composites of CNTs [12-14] and other nanoscale materials [15-17]. The field enhancement factor, basically arises due to sharp tip/protrusions of nanotubes on the surface. A large value of $\beta$ implies higher field concentration which leads to reduce the effective threshold voltage for emission. Modern commercial field emitter demands low turn-on field, low threshold field, high emission current and good current stability. It has been reported that the FE stability of CNTs can be further enhanced if a composite structure is made with oxide however compromising drastically with field enhancement factor [15]. Therefore, it is important to engineer the FE material in such a manner that the trade-off between field enhancement and stability can be optimized. It is also important to correlate FE properties with microstructure.

Nanoscale zinc oxide $(\mathrm{ZnO})$ is semiconducting material which has a wide band gap of $3.37 \mathrm{eV}$ and large exciton binding energy of $60 \mathrm{meV}[18]$ and work function of $5.3 \mathrm{eV}$ [19]. $\mathrm{ZnO}$, as an oxide, presents many remarkable characteristics due to its high mechanical strength, good optical quality, chemical stability and excellent piezoelectric properties [20-22]. Nanostructured $\mathrm{ZnO}$ films have been demonstrated as promising field emitter because of some of the unique properties mentioned above [23]. Based on density functional theory (DFT), Zhang et. al. have reported that $\mathrm{ZnO}$-CNT nanocomposite could be used as a good field emitter (in terms of emission current, enhancement factor and stability) and a potential candidate of FE based devices [24]. There are a numbers of methods to synthesize of CNTs like arc discharge method [2], thermal vapor deposition method [25-26], microwave enhanced plasma chemical vapor deposition (MWPECVD) [27], pulsed laser deposition method (PLD) [28], plasma enhanced chemical vapor deposition method [29] etc.

In general, for metal and oxide coating on CNT for modifying field emission properties, $\mathrm{RF} /$ reactive sputtering techniques are used $[\mathbf{1 0}, \mathbf{3 0}]$. In this work thermal evaporation method is used to coat metallic $\mathrm{Zn}$ on CNT and later Zn-CNT film is oxidized at high temperature to obtain $\mathrm{ZnO}-\mathrm{CNT}$ film. Since this technique does not involve any plasma or high voltage processing (like sputtering), is not prone to damage of CNT. This is also rather cost-effective and relatively simpler technique.

The present work originates with two important objectives: (i) to optimize field enhancement factor and stability and (ii) to understand influence of microstructure on FE properties. To achieve these, we performed a detailed field emission study of pristine carbon nanotubes (p-CNTs) grown on p-Si (100), zinc coated on the top of $\mathrm{p}$ CNTs (Zn-CNT) and zinc oxide coated p-CNTs (ZnOCNT). The turn on field, emission current density and FE stability of all these films are reported. These results are correlated with their microstructure revealed by Raman spectroscopy and transmission electron microscopy. To the best of our knowledge, the metal ( $\mathrm{Zn})$ and oxide coating by this method, for a comprehensive analysis for all field emission parameters along with temporal stability is reported for the first time.

\section{Experimental}

\section{Materials}

The following materials have been used for the present study; p-Si: (University wafer, resistivity: 1-100 ohm$\mathrm{cm}$, South Boston, MA 02127), Zinc dust (Qualigens Fine Chemicals, prod. No.: 28765, 99\%, Mumbai), Argon gas (Sigma Gas and Services 99.999\%, (Grade I), place of manufacturing: New Delhi), Hydrogen gas (Sigma Gas and Services, 99.999\% (Grade I), New Delhi), Acetylene Gas (Sigma Gas and Services, 99.999\% (Grade I), New Delhi).

\section{Methods}

A set of multi walled CNT films were grown by microwave plasma enhanced chemical vapor deposition (MWPECVD) using iron coated $\mathrm{p}-\mathrm{Si}(100)$ as a substrate. The microwave power of $550 \mathrm{~W}$ was applied to generate the plasma at 1.0 Torr at $2.45 \mathrm{GHz}$ frequency. The samples were pretreated in the presence of hydrogen and argon plasma at $720^{\circ} \mathrm{C}$ for $15 \mathrm{~min}$ at 2.5 Torr. The reactant gases were a mixture of hydrogen and acetylene with a ratio of 1:5 at a pressure of 5.0 Torr, almost in the similar environment reported in earlier work [17].

The samples were divided into three parts. First part, the pristine carbon nanotubes is named as p-CNT. A thin layer $(\sim 4 \mathrm{~nm})$ of zinc $(\mathrm{Zn})$ was coated on the rest two parts by the thermal evaporation technique at base pressure of $4 \times 10^{-6}$ Torr. One among those two Zn coated CNT samples kept for the analysis, was named as $\mathrm{Zn}-\mathrm{CNT}$. The other onewasannealed at $520^{\circ} \mathrm{C}$ for 60 minutes to get zinc oxide ( $\mathrm{ZnO})$ coated CNT films. This last sample was named as ZnO-CNT.

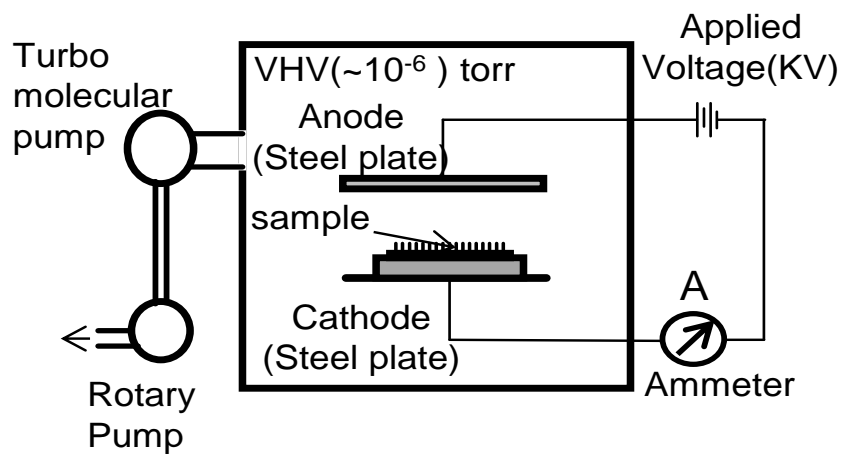

Fig. 1. A schematic of FE set up in diode geometry used for field emission study. 
Scanning electron microscope (SEM) (ZEISS EVO 50 operating at $20 \mathrm{kV}$ accelerating voltage by secondary electron imaging) (resolution 2nm @ 30kV secondary electron with $\mathrm{LaB}_{6}$ ) and high resolution transmission electron microscopy (HRTEM) (Tecnai G220 S-Twin Model operated at $200 \mathrm{kV}$ ) (resolution $0.8 \mathrm{~nm}$ ) studies were performed to examine morphology and microstructure of the films. Presence of $\mathrm{Zn}$ and $\mathrm{O}$ along with $\mathrm{C}$ was confirmed by energy-dispersive X-ray spectroscopy (EDX) studies. Micro-Ramanspectroscopy (T64000 Jobin-Yvon triple monochromator system using $\mathrm{Ar}^{+}$laser at $514.5 \mathrm{~nm}$ excitation wavelength (with a precision of $1 \mathrm{~cm}^{-1}$ ) analysis was carried outto understand the structure of the films.

Field emissions (FE) from these films were studied usinganindigenously developed high vacuum compatible FE set up in diode geometry (Fig. 1).The distance between anode and the sample (cathode) was kept constant at 200 $\mu \mathrm{m}( \pm 5 \mu \mathrm{m})$ using a high precision microcontroller based motion system. The electric field was varied from 1.75 $\mathrm{V} / \mu \mathrm{m}$ to $15 \mathrm{~V} / \mu \mathrm{m}$ at a constant pressure of $1 \times 10^{-6}$ Torr. Direct current (DC) voltage (with a voltage precision of 1 V) was given by an Aplab High Voltage DC Power Supply $(\mathrm{H} 5 \mathrm{KO} 2 \mathrm{~N})$. The current generated on the anode by field emission process is measured by Keithley current meter (model no. 196System DMM). Further, the temporal stability of field emission current was checked by monitoring the fluctuation of current density at each 10 second (with precision of $1 \mathrm{~ms}$ ) interval for 5 hours at a constant electric field. The field emission at different electric field and current stability measurements were controlled by two separate computer controlled program and all parameters have been estimated using software.

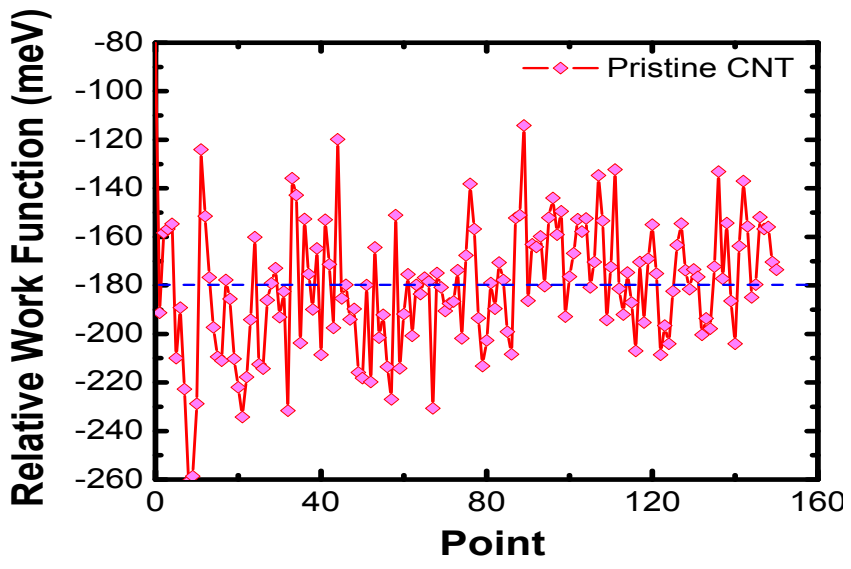

Fig. 2. Relative work function of pristine CNT film with respect to Gold $\mathrm{Au})$ at a point versus point number plot in Kelvin probe measurement.

The work function of p-CNT is measured using Kelvin Probe measurement (KP Technology, Model: KP020) technique. In this measurement, gold probe is used as reference. From the Fig. 2, the mean work function of pCNT sample is $-180 \mathrm{meV}$ with respect to gold. The gold has work function $5.1 \mathrm{eV}$. Hence the work function of the $\mathrm{p}$-CNT sample is $(4.92 \pm 0.003) \mathrm{eV}$. Work functions of other two films are calculated from FE data as discussed later.

\section{Results and discussion}

\section{Morphology and microstructure}

The SEM micrographs of these three sets of films (p-CNT, $\mathrm{Zn}-\mathrm{CNT}$ and ZnO-CNT) are shown in Fig. 3(A, B and $\mathbf{C})$. Formation of CNT is clearly visible in the Fig. 3(A). The growth of CNTs involves the use of the iron nanoparticles, which act as catalyst [17]. When acetylene gas is impinged, the carbon radicals diffuse into the $\mathrm{Fe}$ nanoparticles reaching to a super saturation limit precipitates out to form CNTs. Under the argon plasma, the dissociation of acetylene in presence of hydrogen is governed by the equation,

$$
\mathrm{C}_{2} \mathrm{H}_{2} \longrightarrow 2 \mathrm{C}+\mathrm{H}_{2}
$$

Formation of CNT is clearly visible in the Fig. 3(A). In Fig. 3(B) and 3(C) a clear change in morphology is observed after coating of $\mathrm{Zn}$ on top of p-CNT films followed by oxidation at high temperature. Evidence of some coating on top of CNTs is seen in Fig. 3(B) and 3(C) for $\mathrm{Zn}-\mathrm{CNT}$ and $\mathrm{ZnO}-\mathrm{CNT}$ films respectively indicating presence of $\mathrm{Zn}$ and/or its oxide.

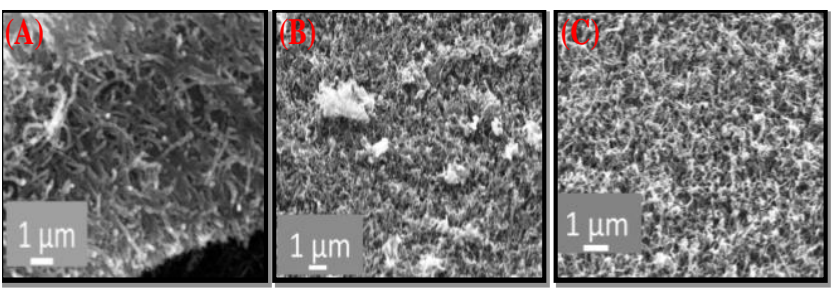

Fig. 3. (A), (B) and (C): SEM micrographs of p-CNT, Zn-CNT and ZnOCNT films respectively.

The evidence of coating is further confirmed by TEM studies. TEM images of the films (p-CNT, Zn-CNT, ZnO$\mathrm{CNT})$ are shown in Fig. 4(A, B and C) respectively. Formation of bamboo shaped MWCNT walls is clearly seen in Fig. 4(A). The encircled black spot in the TEM image of the p-CNT sample is due to catalyst $(\mathrm{Fe})$. In case of Zn-CNT and ZnO-CNT some black spots (encircled) at the top of the CNTs in their respective images are clearly seen, which can be attributed to $\mathrm{Zn}$ and $\mathrm{ZnO}$ coatings on MWCNT films.

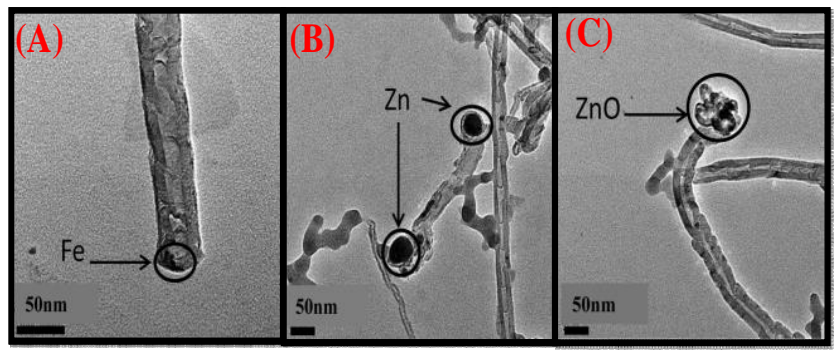

Fig. 4. (A), (B) and (C): TEM micrographs of p-CNT, Zn-CNT and ZnOCNT films respectively.

The presence of $\mathrm{Zn}$ in $\mathrm{Zn}-\mathrm{CNT}$ and $\mathrm{Zn}, \mathrm{O}$ in $\mathrm{ZnO}-\mathrm{CNT}$ films is confirmed from EDX analysis. The EDX spectra corresponding to $\mathrm{p}-\mathrm{CNT}$, Zn-CNT, ZnO-CNT films are shown in Fig. 5. 


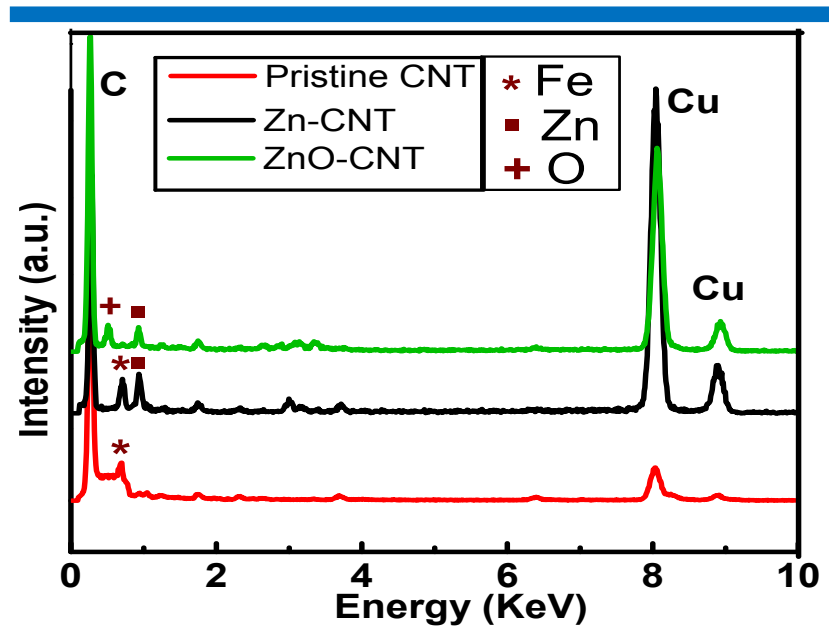

Fig. 5. EDX spectra of p-CNT, Zn-CNT and $\mathrm{ZnO}-\mathrm{CNT}$ films respectively.

Raman spectra of these films are shown in Fig. 6. The two dominant peaks in all Raman spectra appear at 1350 $\mathrm{cm}^{-1}$ and $1580 \mathrm{~cm}^{-1}$, which are designated as D and G peak [31], and generally present in all multiwall nanotubes. The G-peak arises because of $E_{2 \mathrm{G}}$ mode of vibration of highly oriented graphite and hence a signature of crystalline graphitic carbon in the films. The D-line is caused by defects in the graphite crystals and by the finite sizes of graphite crystallites in the material. The strength of the Dline relative to the G-line (intensity ratio: $\mathrm{I}_{\mathrm{D}} / \mathrm{I}_{\mathrm{G}}$ ) is a measureof the amount of disorder in the carbon nanotube [32]. The $\mathrm{I}_{\mathrm{D}} / \mathrm{I}_{\mathrm{G}}$ values corresponding to $\mathrm{p}$-CNT, Zn-CNT and $\mathrm{ZnO}-\mathrm{CNT}$ as calculated from the spectra are $0.77,1.03$ and 0.96 respectively.

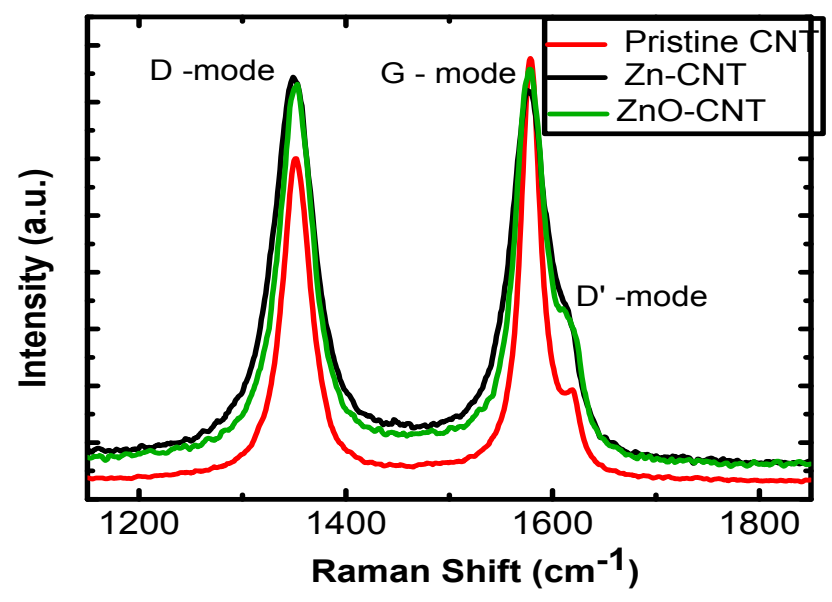

Fig. 6. Raman spectra of p-CNT, Zn-CNT and ZnO-CNT films respectively.

Nakanishi et al. shows that the emission current increases with improve in crystallinity of the sample [33]. In the present case, in-plane crystallite size $L$ is estimated from the ratio of the intensities $\mathrm{I}_{\mathrm{G}}$ and $\mathrm{I}_{\mathrm{D}}$ of the G- and Dlines respectively as given in the literature [32],

$$
L=4.4 \times\left(\mathrm{I}_{\mathrm{D}} / \mathrm{I}_{\mathrm{G}}\right)
$$

The values of the crystallite size calculated from this equation for p-CNT, Zn-CNT and ZnO-CNT and are shown in Table 1. These values indicate deterioration of crystallinity of the coated films with respect to their pristine counterpart.

Table 1. Field emission parameters, $\mathrm{I}_{\mathrm{D}} / \mathrm{I}_{\mathrm{G}}$ and in plane crystallite size $(L)$ of p-CNT, Zn-CNT, ZnO-CNT films.

\begin{tabular}{|c|c|c|c|c|c|c|c|c|c|}
\hline \multirow{2}{*}{$\begin{array}{l}\text { Sample } \\
\text { Name }\end{array}$} & \multirow{2}{*}{$\begin{array}{l}\text { Turn-on } \\
\text { Field } \\
(\mathrm{V} / \mu \mathrm{m})\end{array}$} & \multirow{2}{*}{$\begin{array}{c}\text { Threshold } \\
\text { Field } \\
(\mathrm{V} / \mu \mathrm{m})\end{array}$} & \multirow{2}{*}{$\begin{array}{c}\text { Enhancement } \\
\text { Factor }\end{array}$} & \multicolumn{4}{|c|}{ Current Fluctuation $c f(\%)$} & \multirow[b]{2}{*}{$\mathrm{I}_{\mathrm{D}} / \mathrm{I}_{\mathrm{G}}$} & \multirow[b]{2}{*}{$L(\mathrm{~nm}$. } \\
\hline & & & & $\begin{array}{c}5.0 \\
\mathrm{~V} / \mu \mathrm{m}\end{array}$ & $7.5 \mathrm{~V} / \mu \mathrm{m}$ & $\begin{array}{c}10.0 \\
\mathrm{~V} / \mu \mathrm{m}\end{array}$ & $12.5 \mathrm{~V} / \mu \mathrm{m}$ & & \\
\hline $\mathrm{p}-\mathrm{CNT}$ & 3.3 & 5.1 & 2847.1 & 64.4 & 15.9 & 8.6 & 7.0 & 0.77248 & 5.696 \\
\hline $\mathrm{Zn}-\mathrm{CNT}$ & 4.3 & 8.2 & 2695.5 & 169.2 & 32.8 & 29.9 & 17.6 & 1.0319 & 4.264 \\
\hline $\mathrm{ZnO}$-CNT & 3.7 & 6.3 & 3801.1 & 16.8 & 6.9 & 9.8 & 3.5 & 0.96513 & 4.559 \\
\hline
\end{tabular}

\section{Field emission}

The work function of the p-CNT is $4.92 \mathrm{eV}$ as estimated from Kelvin-Probe method. The work function of both $\mathrm{Zn}$ CNT and ZnO-CNT sample can be estimated from the formula (which can be derived from the eq. (1)),

$$
\varphi_{2}=\varphi_{1} \times\left(\frac{\text { slope }_{2}}{\text { slope }_{1}}\right)^{2 / 3}
$$

where $\varphi_{1}$ is the work function of the first sample, $\varphi_{2}$ is the work function of the second sample, slope $e_{1}$ is the slope of the FN plot for the first sample, slope $_{2}$ is the slope of the FN plot of the second sample. By using this formula, the work function of $\mathrm{Zn}-\mathrm{CNT}$ and $\mathrm{ZnO}-\mathrm{CNT}$ films are found to be $5.18 \mathrm{eV}$ and $4.89 \mathrm{eV}$ respectively.

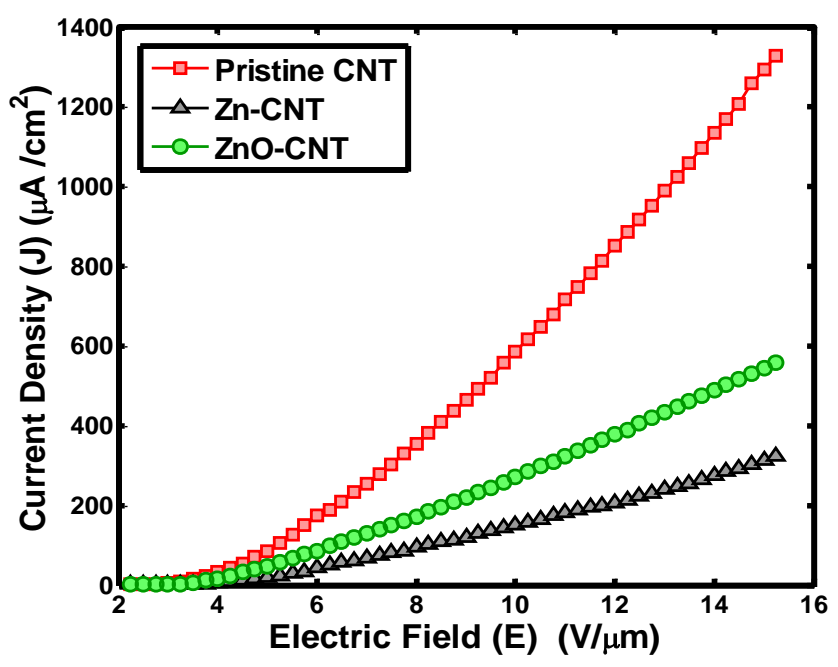

Fig. 7. Average FE current density versus electric field for p-CNT, ZnCNT and $\mathrm{ZnO}-\mathrm{CNT}$ films.

The variation of average current density versus electric field for p-CNT, Zn-CNT and ZnO- CNT is shown in Fig. 7. It is evident from the figure that at an electric field $15 \mathrm{~V} / \mu \mathrm{m}$, the current density of $\mathrm{p}-\mathrm{CNT}$ is maximum $(\sim 1300$ $\left.\mu \mathrm{A} / \mathrm{cm}^{2}\right)$, whereas that for $\mathrm{Zn}-\mathrm{CNT}$ is minimum $(\sim 300$ $\left.\mu \mathrm{A} / \mathrm{cm}^{2}\right)$ and for $\mathrm{ZnO}-\mathrm{CNT}$ this value is intermediate $(\sim 575$ 
$\mu \mathrm{A} / \mathrm{cm}^{2}$ ). The turn-on field (electric field required to produce $10 \mu \mathrm{A} / \mathrm{cm}^{2}$ current density) and the threshold field (electric field required to produce $100 \mu \mathrm{A} / \mathrm{cm}^{2}$ current density) calculated from this plot are found to be maximum for the Zn-CNT sample $(4.3 \mathrm{~V} / \mu \mathrm{m}$ and $8.2 \mathrm{~V} / \mu \mathrm{m})$ and minimum for p-CNTs $(3.3 \mathrm{~V} / \mu \mathrm{m}$ and $5.1 \mathrm{~V} / \mu \mathrm{m})$. For $\mathrm{ZnO}$ CNT sample the turn-on and threshold fields are $3.7 \mathrm{~V} / \mu \mathrm{m}$ and $6.3 \mathrm{~V} / \mu \mathrm{m}$ respectively, which are greater than those for p-CNTs but lower than that for Zn-CNT.

The Fowler-Nordheim (F-N) plots of p-CNT, Zn-CNT and $\mathrm{ZnO}-\mathrm{CNT}$ films are shown in Fig. 8 (A, B and $\mathbf{C}$ ) respectively. The field enhancement factor $(\beta)$ is calculated for all three samples from straight line fits as shown in Fig. 8. The reason for different slope for $\mathrm{Zn}-\mathrm{CNT}$ and $\mathrm{ZnO}-$ CNT sample is due to space charge effect, surface adsorbates, damage to emission sites etc [34]. It is seen that $\beta$ value is maximum (in the high field region) in $\mathrm{ZnO}-\mathrm{CNT}$ sample (3108) and lowest for Zn-CNT sample (2695), whereas it is intermediate (2847) for p-CNTs sample. The turn on field, threshold field and enhancement factor are given in Table 1.
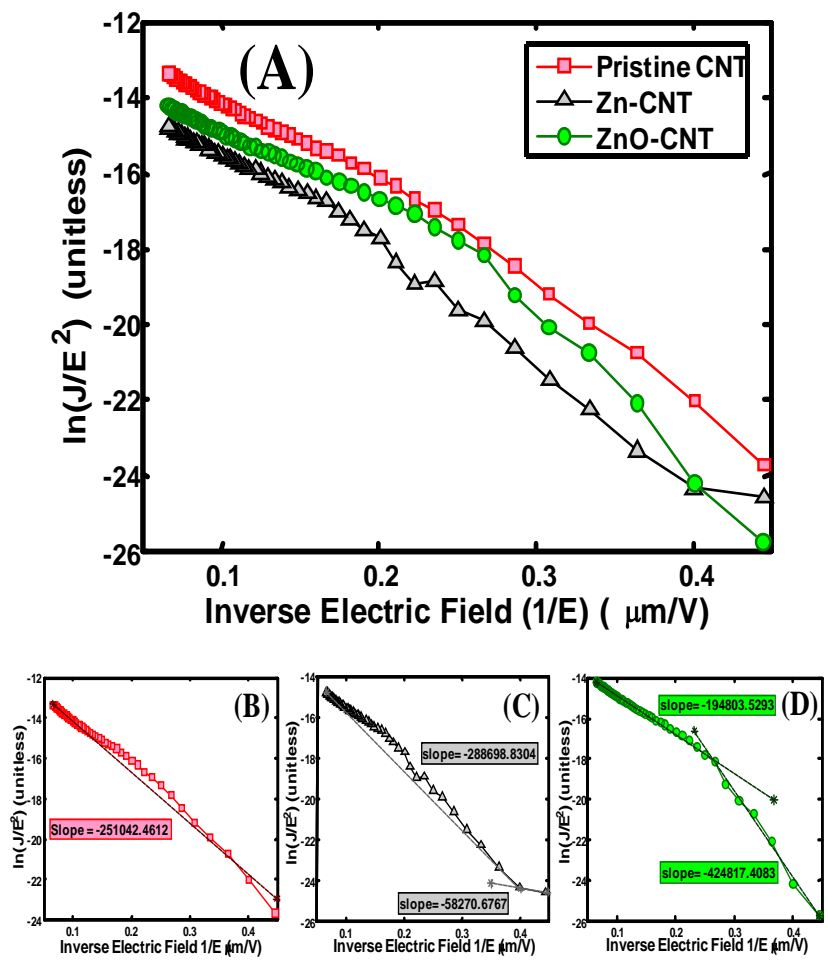

Fig. 8. (A) Average F-N plot of p-CNT, Zn-CNT and ZnO-CNT films. (B) Average F-N plot of p-CNT film. The straight line is fitted at one portion to calculate $\beta$ value of this film. (C) Average F-N plot of Zn-CNT film. The straight line is fitted at two different portions to calculate $\beta$ values of this film. (D) Average F-N plot of $\mathrm{ZnO}-\mathrm{CNT}$ film. The straight line is fitted at two different portions to calculate $\beta$ values of this film.

In order to study the FE current stability, an electric field is applied to each of the samples and the current is recorded for 5 hours at each 10 second interval. We have performed this measurement for four particular electric fields $(5.0 \mathrm{~V} / \mu \mathrm{m}, 7.5 \mathrm{~V} / \mu \mathrm{m}, 10.0 \mathrm{~V} / \mu \mathrm{m}, 12.5 \mathrm{~V} / \mu \mathrm{m}$, $)$. The current versus time for these three films under above mentioned electric fields is shown in Fig. 9.

For each current profile the mean value is calculated and indicated by dotted lines. The fluctuation of the current $\operatorname{density}(c f)$ over the mean value was calculated for these three films at each electric field by the formula,

$$
c f=\frac{|(x-\bar{x})|}{\bar{x}} \times 100 \%
$$

where $x$ is the maximum deviated data from the mean value $\bar{x}$ and $c f$ stands for current fluctuation (in \%). The $c f$ values calculated at various electric fields are given in Table 1. The results show that the $c f$ is quite low in p-CNT film, whereas in Zn-CNT $c f$ enhances appreciably indicating deterioration of FE current stability. However, in $\mathrm{ZnO}$ CNT $c f$ again decreases and becomes minimum among these three samples and hence it has maximum current stability. Also, it is clear from the result that at higher electric field value the current fluctuation decreases for all the three samples.

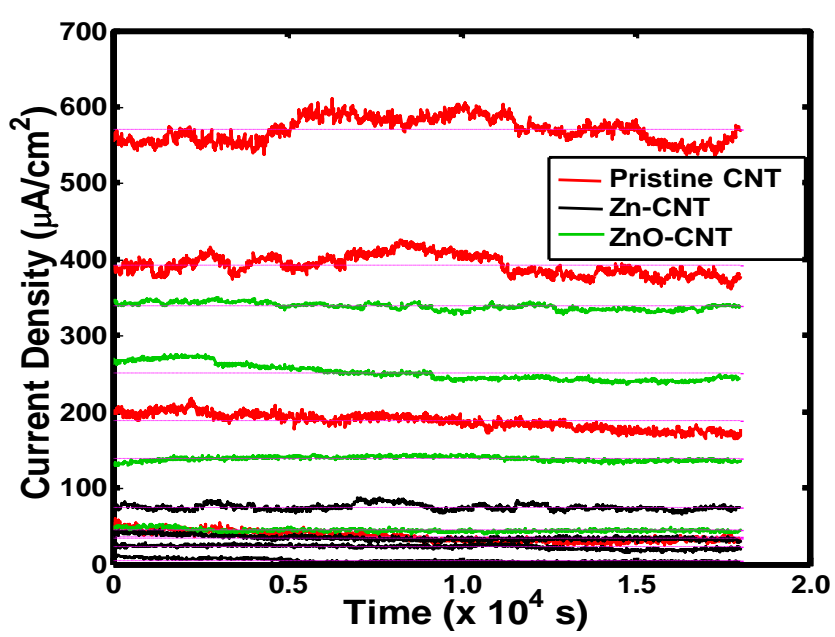

Fig. 9. FE current density versus time plot for $\mathrm{p}-\mathrm{CNT}, \mathrm{Zn}-\mathrm{CNT}$ and $\mathrm{ZnO}-$ CNT films at anode-cathode distance $=200 \mu \mathrm{m}$ to determine stability of these films.

\section{Correlation between microstructure and field emission}

The field emission property shown above is correlated with workfunction and microstructure of the films in the following way. In Zn-CNT film work function increase and also in-plane crystalline size diminishes, thereby decreasing the field emission current. In case of $\mathrm{ZnO}-\mathrm{CNT}$, the FE current is recovered because of better crystallinity and lowering of work function with respect to Zn-CNT film. Because of lowest work function, the pristine film gives highest FE current. The decrease in $\beta$ value in case of $\mathrm{Zn}$ CNT and a significant rise of the same in $\mathrm{ZnO}-\mathrm{CNT}$ film as compared to their uncoated counterparts can be understood from the schematic diagram as depicted in (Fig. 10). It is clear from this figure that the aspect ratio enhances due to oxide coating. Moreover, as $\mathrm{ZnO}$ is coated at the tip and the side of the CNT wall, the overall current stability enhances. The best design of a field emitting material is a trade-off between FE current density and stability. In the present case although the current density in $\mathrm{ZnO}-\mathrm{CNT}$ is less as compared to its pristine counterpart, the stability is enhanced appreciably because of $\mathrm{ZnO}$ coating. Therefore, with increase in stability and field enhancement factor it can be commented that the approach adopted here to make 
a $\mathrm{ZnO}-\mathrm{CNT}$ is well justified for making a better CNT based field emission material.

$\mathrm{CNT} \rightarrow$

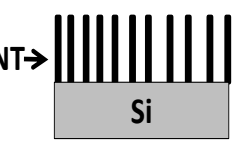

Pristine CNT

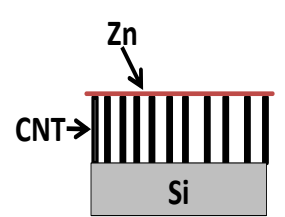

Zn-CNT

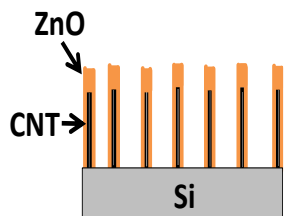

ZnO-CNT
Fig. 10. Schematic view of possible surface of these three films (for $p$ CNT, Zn-CNT and ZnO-CNT).

In case of pristine CNT, current density is generally higher than its composites. However, for practical application purpose a better temporal stability is required, which is not good in as grown CNT samples. A comparative analysis of various parameters obtained in $\mathrm{ZnO}-\mathrm{CNT}$ composites as reported by various authors is made in Table 2. It is evident that for our $\mathrm{ZnO}-\mathrm{CNT}$ films, threshold field is comparable, maximum current density and enhancement factor are higher than most of the other cases. The most important investigation in the present case is low current fluctuation, i.e. high temporal stability. This is significantly higher as compared to pristine and $\mathrm{Zn}$ coated CNT films. A systematic investigation of this quantity along with all other FE parameters is hardly found in the existing literature.

Table 2. A comparative analysis of field emission parameters of $\mathrm{ZnO}$ CNT composites samples.

\begin{tabular}{|c|c|c|c|c|}
\hline $\mathrm{ZnO}-\mathrm{CNT}$ & $\begin{array}{c}\text { Current } \\
\text { Fluctuation } \\
\text { (a) } 12 \mathrm{~V} / \mu \mathrm{m}\end{array}$ & $\begin{array}{l}\text { Threshold Field } \\
\qquad(\mathrm{V} / \mathrm{\mu m})\end{array}$ & $\begin{array}{l}\text { Maximum Current } \\
\text { Density } \\
\left(\mu \mathrm{A} / \mathrm{cm}^{2}\right)\end{array}$ & $\begin{array}{c}\text { Enhancement } \\
\text { Factor }\end{array}$ \\
\hline $\begin{array}{c}\text { Huang et. } \\
\text { al. [4] }\end{array}$ & $\begin{array}{c}\text { Not } \\
\text { Investigated }\end{array}$ & Not Reported & 400 & 4490 \\
\hline $\begin{array}{c}\text { Ling-min et. } \\
\text { al. [35] }\end{array}$ & $\begin{array}{c}\text { Not } \\
\text { Investigated }\end{array}$ & $\sim 4.8$ & 18.16 (Area $\left.=12 \mathrm{~cm}^{2}\right)$ & Not Reported \\
\hline $\begin{array}{c}\text { Wu et. al. } \\
\text { [36] }\end{array}$ & $\begin{array}{c}\text { Not } \\
\text { Investigated }\end{array}$ & 5.4 & 3500 & 2688 \\
\hline $\begin{array}{c}\text { Green et. al. } \\
\text { [37] }\end{array}$ & $\begin{array}{c}\text { Not } \\
\text { Investigated }\end{array}$ & 5.0 & 120 & 1920 \\
\hline Patra et.al. & $3.5 \%$ & 6.3 & 560 & 3801 \\
\hline
\end{tabular}

\section{Conclusion}

Detailed field emission studies on three films designated as p-CNT, Zn-CNT and ZnO-CNT are performed. It has been observed that the field emission current stability is highest in case of ZnO-CNT and lowest in $\mathrm{Zn}-\mathrm{CNT}$. The field enhancement factor is highest in $\mathrm{ZnO}-\mathrm{CNT}$ film, followed by $\mathrm{p}-\mathrm{CNT}$ and $\mathrm{Zn}-\mathrm{CNT}$. The deterioration of crystallinity of $\mathrm{Zn}-\mathrm{CNT}$ and $\mathrm{ZnO}-\mathrm{CNT}$ as compared to their pristine counterpart as revealed by Raman spectroscopy results in decrease in field emission current. However, the field enhancement factor in $\mathrm{ZnO}-\mathrm{CNT}$ enhances due to increase in aspect ratio. All these results are well correlated and suggest that this approach leads to obtain a better CNT composite based field emitter for future applications.

\section{Acknowledgements}

We acknowledge financial support from CSIR, India and DST, India sponsored TEM facility of IIT Delhi, India and useful discussion with Dr. A. K. Shukla, Department of Physics, IIT Delhi for Raman spectroscopy.

\section{Reference}

1. Xia, Y.; Yang, P.;Sun, Y.; Wu, Y.; Mayers, B.; Gates, B.; Yin, Y.; Kim, F.; Yan, H. Adv. Mater. 2003, 15, 353. DOI: $10.1002 /$ adma.200390087

2. Ijima, S. Nature 1991, 354, 56 . DOI: $10.1038 / 354056 \mathrm{a} 0$

3. Rinzler, A. G.; Hanfer, J. H.; Nikolaev, P.; Lou, L.; Kim, S. G.; Tomanek, D.; Nordlander, P.; Colbert, D. T.; Malley, R. E. Science 1995, 269, 1550.

DOI: $\underline{10.1126 / \text { science. } 269.5230 .1550}$

4. Huang, C. S.; Yeh, C. Y.; Chang, Y. H.; Hsieh, Y.M.; Ku, C.Y.; Lai, Q.T. Diam. Relat. Mater. 2009, 18,452. DOI: $10.1016 /$ i.diamond.2008.10.058

5. deHeer, W. A.; Chatelain, A.; Ugate, D. Science 1995, 270, 1179 DOI: $10.1126 /$ science. 270.5239 .1179

6. Cheng, Y.; Zhou, O. C. R. Physique 2003, 4, 1021. DOI: $10.1016 / \mathrm{S} 1631-0705(03) 00103-8$

7. Lysenkov, D.; Müller, G. Int. J. Nanotechnology 2005, 2, 239 DOI: $10.1504 /$ IJNT.2005.008062

8. Fowler, R. H.; Nordheim, L. P. Roy. Soc. Lond. A 1928, 119, 173 URL: http://www.jstor.org/stable/95023

9. Rui, G. G.; Toshimichi, I. Chinese Phys. B 2009, 18, 4547. DOI: $10.1088 / 1674-1056 / 18 / 10 / 075$

10. Uh, H.S.; Park, S.; Kim, B. Diam. Relat. Mater. 2010, 19, 586. DOI: $10.1016 /$. diamond.2009.11.021

11. Rakhi, R. B.; Reddy, A. L. M.; Shaijumon, M. M.; Sethupathi, K.; Ramaprabhu, S. J. Nanopart. Res. 2008, 10, 179. DOI: $10.1007 / \mathrm{s} 11051-007-9240-8$

12. Lei, W.; Zhang, X.; Zhao, Z.; Chen, J.; Cui, Y.; Wang, B. J. Nanosci. Nanotechnol. 2012, 12, 6453. DOI: $10.1166 / \mathrm{jnn} .2012 .5426$

13. Baby, T. T.; Rakhi, R. B.; Ravi, N.; Ramaprabhu, S. J. Nanosci. Nanotechnol. 2012, 12, 6718. DOI: $10.1166 /$ jnn.2012.4541

14. Park, T.; Sim, K.; Lee, J.; Yi, W. J. Nanosci. Nanotechnol. 2012, 12 , 5812.

DOI: $\underline{10.1166 / j n n .2012 .6338}$

15. Li, C.; Fang, G.; Yuan, L.; Liu, N.; Ai, L.; Xiang, Q.; Zhao, D.; Pan, C.; Zhao, X. Nanotechnology 2007, 18, 155702. DOI: $10.1088 / 0957-4484 / 18 / 15 / 155702$

16. Ho, Y. M.; Zheng, W. T.; Li, Y. A.; Liu, J. W.; Qi, J. L. J. Phys. Chem. C 2008, 112, 17702 . DOI: $10.1021 / \mathrm{jp} 804566 \mathrm{k}$

17. Sharma, H.; Kaushik, V.; Girdhar, P.; Singh, V. N.; Shukla, A. K.; Vankar, V. D. Thin Solid Films 2010, 518, 6915. DOI: $10.1016 / \mathrm{j} . \mathrm{tsf} .2010 .07 .043$

18. Wang, C.Y.; Adhikari, S. Phys. Lett. A 2011, 375, 2171. DOI: $10.1016 / j$.physleta.2011.04.031

19. Lee, C. J.; Lee, T. J.; Lyu, S. C.; Zhang, Y.; Ruh, H.; Lee, H. J. Appl. Phys. Lett. 2002, 81,3648 DOI: $10.1063 / 1.1518810$

20. Pearton, S. J.; Norton, D. P.; Ip, K.; Heo, Y. W.; Steiner, T. Superlattice Microst. 2003, 34, 3. DOI: $10.1016 /$ S0749-6036(03)00093-4

21. Srivastava, A. K.; Deepa, M.; Sood, K. N.; Erdem, E.; Eichel, R. A. Adv. Mat. Lett. 2011, 2(2), 142. DOI: 10.5185 /amlett.2011.1201

22. Wahab, R.; Hwang, I. H.; Shin, H. S.; Kim, Y. S.; Musarrat, J.; AlKhedhairy A. A.; Siddiqui, M. A.; In Intelligent Nanomaterials; Tiwari, A.; Mishra, A. K.; Kobayashi, H.; Turner, A. P. F. (Eds.); Wiley-Scrivener Publishing LLC, USA, 2012, Chap. 5, pp. 183-212, ISBN 978-04-709387-99. DOI: $\underline{10.1002 / 9781118311974 . \operatorname{ch} 5}$ 
23. Premkumar, T.; Zhou, Y.S.; Lu, Y. F.; Baskar, K. ACS Appl. Mater. Interfaces. 2010, 2, 2863.

DOI: $10.1021 / \mathrm{am} 100539 \mathrm{q}$

24. Zhang, S.; Zhang, Y.; Huang, S.; Liu, H.; Wang, P.; Tian, H. Carbon 2011, 49, 3855.

DOI: $10.1016 /$ j.carbon.2011.05.018

25. Handuja, S.; Srivastava, P.; Vankar, V. D. Nanoscale Res. Lett. 2010, 5, 1211.

DOI: $10.1007 / \mathrm{s} 11671-010-9628-8$

26. Conroy, D.; Moisala, A.; Cardoso, S.; Windle, A.; Davidson, J. Chem. Eng. Sci. 2010, 65, 2965.

DOI: $10.1016 /$ j.ces.2010.01.019

27. Srivastava, S. K.; Shukla, A. K.; Vankar, V. D.; Kumar, V. Thin Solid Films 2006, 515, 1552.

DOI: $10.1016 / j . t s f .2006 .05 .009$

28. Puretzky, A. A.; Geohegan, D. B.; Fan, X.; Pennycook, S. J. Appl. Phys. Lett. 2000, 76, 182.

DOI: $10.1063 / 1.125696$

29. Meyyappan, M.; Delzeit, L.; Cassell, A.; Hash, D. Plasma Sources Sci. Technol. 2003, 12, 205. DOI: $10.1088 / 0963-0252 / 12 / 2 / 312$

30. Zhu, Y.; Elim, H. I.; Foo, Y. L.; Yu, T.; Liu, Y.; Ji, W.; Lee, J. Y.; Shen, Z.; Wee, A. T. S.; Thong, J. T. L.; Sow, C. H. Adv. Mater. 2006, $18,587$.

DOI: $10.1002 /$ adma.200501918

31. Dresselhaus, M. S.; Jorio, A.; Saito, R. Ann. Rev. Cond. Mat. Phys. 2010, 1,89 .

DOI: $10.1146 /$ annurev-conmatphys-070909-103919

32. Sveningsson, M.; Morjan, R. E.; Nerushev, O.A.; Sato, Y.; Bäckström, J.; Campbell, E. E. B.; Rohmund, F. Appl. Phys. A: Mater. Sci. Process. 2001, 73, 409. DOI: $10.1007 / \mathrm{s} 003390100923$

33. Nakanishi, Y.; Miyake, A.; Kominami, H.; Aoki, T.; Hatanaka, Y.; Shimaoka, G. Appl. Surf. Sci. 1999, 142, 233.

DOI: $10.1016 / \mathrm{S} 0169-4332(98) 00654-0$

34. Jha, M.; Patra, R.; Ghosh, S.; Ganguli, A. K. J. Mater. Chem. 2012, 22,6356

DOI: $10.1039 / \mathrm{C} 2 \mathrm{JM} 16538 \mathrm{D}$

35. Ling-min, Y.; Chang-chun, Z. Proceeding of the $20094^{\text {th }}$ IEEE International Conference on Nano/Micro Engineered and Molecular Systems, 2009, ISBN: 978-1-4244-4629-2.

DOI: $10.1109 / \mathrm{NEMS} .2009 .5068515$

36. Wu, C.; Li, F.; Zhang, Y.; Guo, T.; Qu, B.; Chen, Z. Appl. Surf. Sci. 2011, 257, 4539 . DOI: j.apsusc.2010.10.092

37. Green, J. M.; Dong, L.; Gutu, T.; Jiao; J.; Conley, J. F. Jr.; Ono, Y. J. Appl. Phys. 2006, 99, 094308.

DOI: $\underline{10.1063 / 1.2194112}$

\section{Advanced Materials Letters}

\section{Publish your article in this journal}

ADVANCED MATERIALS Letters is an international journal published quarterly. The journal is intended to provide top-quality peer-reviewed research papers in the fascinating field of materials science particularly in the area of structure, synthesis and processing, characterization, advanced-state properties, and applications of materials. All articles are indexed on various databases including $\mathrm{DOAJ}$ and are available for download for free. The manuscript management system is completely electronic and has fast and fair peer-review process. The journal includes review articles, research articles, notes, letter to editor and short communications. 